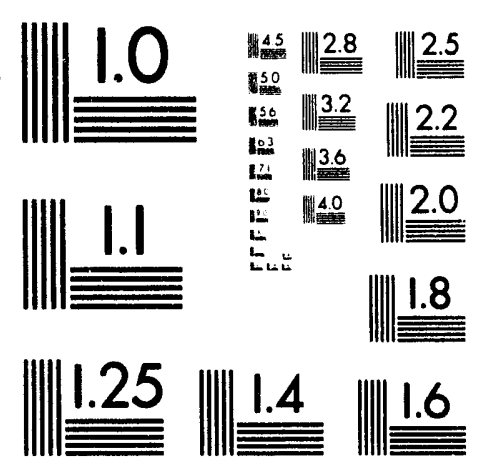



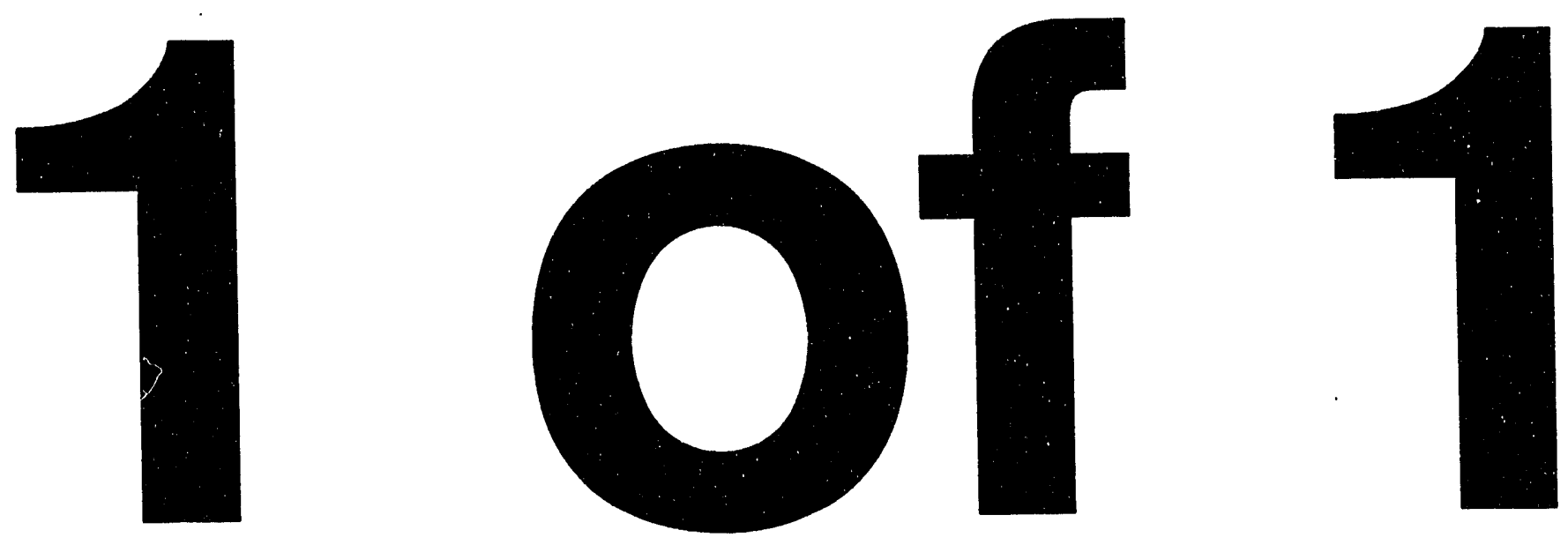
ANL/EAIS/TM-101

-

Summary Evaluation of the Video,

Transportation of Radioactive and Hazardous Materials: Safety for All Concerned

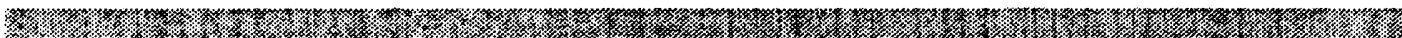

by M.C. Monroe and C.F. Yourig

Environmental Assessment and Information Sciences Division,

Argonne National Laboratory, 9700 South Cass Avenue, Argonne, Illinois 60439

July 1993 Work sponsored by United States Department of Energy,
Assistant Secretary for Environmental Restoration and Waste Management, Transportation Management Division 


\section{CONTENTS}

FOREWORD AND ACKNOWLEDGMENTS $\ldots \ldots \ldots \ldots \ldots \ldots \ldots \ldots \ldots$ v

NOTATION $\ldots \ldots \ldots \ldots \ldots \ldots \ldots \ldots \ldots \ldots \ldots \ldots \ldots \ldots \ldots \ldots \ldots \ldots \ldots \ldots$

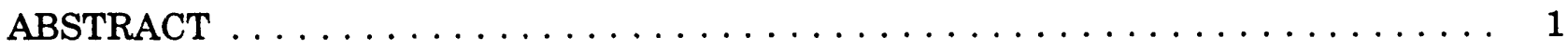

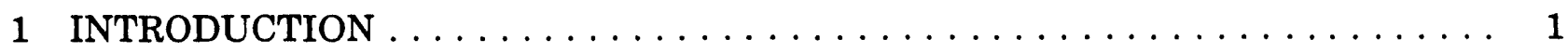

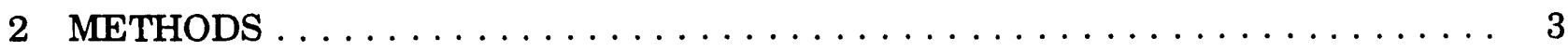

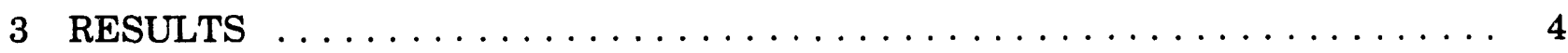

3.1 Types of Respondents $\ldots \ldots \ldots \ldots \ldots \ldots \ldots \ldots \ldots \ldots \ldots \ldots \ldots$

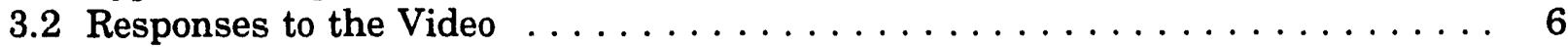

3.2.1 Ratings on Numerical Scales $\ldots \ldots \ldots \ldots \ldots \ldots \ldots \ldots \ldots \ldots$

3.2.2 Responses to Open-Ended Questions $\ldots \ldots \ldots \ldots \ldots \ldots \ldots \ldots 6$

3.3 Summary of Results $\ldots \ldots \ldots \ldots \ldots \ldots \ldots \ldots \ldots \ldots \ldots, \ldots \ldots \ldots$

4 RECOMMENDATIONS $\ldots \ldots \ldots \ldots \ldots \ldots \ldots \ldots \ldots \ldots \ldots \ldots \ldots \ldots \ldots$

4.1 Revising the Video $\ldots \ldots \ldots \ldots \ldots \ldots \ldots \ldots \ldots \ldots \ldots \ldots \ldots \ldots$

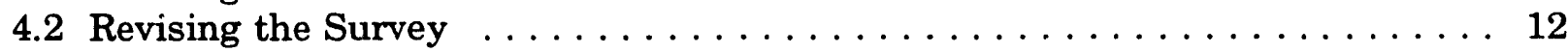

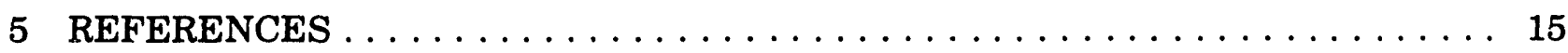

APPENDIX A: Modern Talking Picture's Survey $\ldots \ldots \ldots \ldots \ldots \ldots \ldots \ldots$

APPENDIX B: Sample of Respondents' Comments on This Video .......... 19

APPENDIX C: Sample of Desired Topics $\ldots \ldots \ldots \ldots \ldots \ldots \ldots \ldots \ldots \ldots \ldots$

APPENDIX D: Sample Questions for a Revised Survey $\ldots \ldots \ldots \ldots \ldots \ldots \ldots$

\section{TABLES}

3.1 Specific Grade Levels Represented by Respondents . . . . . . . . . . . . . . 4

3.2 Subjects in Which Video Was Shown by Respondents $\ldots \ldots \ldots \ldots \ldots \ldots \ldots$

3.3 States Where 25 or More Respondents Requested the Video ........... 5

3.4 Ratings of General Reaction to the Video $\ldots \ldots \ldots \ldots \ldots \ldots \ldots \ldots$ 


\section{FOREWOR.) AND ACKNOWLEDGMENTS}

This report provides the U.S. Department of Energy's (DOE's) Office of Environmental Restoration and Waste Management, Transportation Management Division, with suggestions for improving its public outreach efforts related to transportation issues, based on an evaluation of a video regarding transportation of radioactive and hazardous materials. This report is intended as a first step in the evaluation of outreach and informational materials. The results reported herein are based on data from a brief survey developed by Modern Talking Picture Service, Inc., on general impressions of the video.

This effort was made possible by the foresight of Judith Holm (Chicago Operations Office, Transportation Management Division; now at the Office of Special Programs, within the Office of Environmental Restoration and Waste Management). Mary Jo Acke (Chicago Operations Office, DOE) and Kristine Lavery (Mac Technical Services Co., Chicago, Illinois) provided thoughtful comments. Roger Carlson, Argonne National Laboratory, was pivotal in developing the video and in establishing the survey procedures. 


\section{NOTATION}

\section{ACRONYMS}

DOE U.S. Department of Energy

HazMat hazardous material

MTP Modern Talking Picture Service, Inc.

SPSS Statistical Package for the Social Sciences 


\title{
SUMMARY EVALUATION OF THE VIDEO, TRANSPORTATION OF RADIOACTIVE AND HAZARDOUS MATERIALS: SAFETY FOR ALL CONCERNED
}

by

M.C. Monroe and C.F. Young

\begin{abstract}
Outreach materials are often developed and distributed without evaluation of their effectiveness. This report provides a glimpse of the effectiveness of one of the U.S. Department of Energy's videos on transportation of radioactive and hazardous materials. Data from a survey developed by Modern Talking Picture Service, Inc. are summarized. This survey was sent to recipients of the video at three to six weeks after they had received and viewed the video. The response rate is unknown; hence, the results suggest the range of perspectives on the video, rather than the representativeness of those perspectives. The results are also limited by incomplete responses to the survey.

Most respondents were middle school and high school teachers who resided throughout the country. Respondents used the video in nearly all school subjects. Most respondents indicated that the video was fairly good and appreciated the factual information, although some saw it as propaganda. Respondents indicated that they would like additional information on hazardous wastes, nuclear power, and transportation. The test crashes were mentioned as a highlight of the video. Recommendations for revising the video and survey are included.
\end{abstract}

\section{INTRODUCTION}

The U.S. Department of Energy's (DOE's) Liaison and Communication Program within the Office of Special Programs is responsible for the development of informational and communication products for various audiences. These informational materials, such as fact sheets, brochures, exhibits, media kits, and videos, communicate the regulations and safety precautions that enable the DOE to responsibly ship radioactive and other hazardous materials across the country. As transportation activities become more complex, it is increasingly important to have high-quality communication products that accurately portray the DOE's efforts and address the public's concerns.

This report summarizes the results of a preliminary evaluation of a video on radioactive and hazardous materials. The findings are based on data from a one-page survey 
developed by Modern Talking Picture Service, Inc. (MTP) and were summarized by Argonne National Laboratory. This is the first in a series of evaluations of the Liaison and Communication Program's informational and communication products. The purpose of these evaluations is to ensure quality materials that accurately communicate the program's mission.

The video, Transportation of Radioactive and Hazardous Materials: Safety for All Concerned, was produced by the Argonne Film and Video Group of the Office of Public Affairs for two audiences: trainers ${ }^{1}$ and the general public. The video has been distributed by MTP free of charge to schools across the country and to other organizations and groups that requested it.

The 22-minute video opens with an explanation that the transportation of hazardous materials (e.g., fingernail polish, smoke detectors) occurs all the time. The film then explains that, although there are relatively few extremely hazardous shipments, government regulations ensure that responsible agencies transport such materials safely. An explanation of radioactivity and allowable exposure is provided before the video details the types of packaging and the labeling regulations that are followed. Another component of the video is a description of the way in which some packages are exposed to water, fire, crashes, and other tests of container integrity. Highway routing and driver training are explained as additional avenues used to protect the public. The video concludes that, should there be an accident, a qualified response team is ready to assist.

In this report, the surveys from MTP are summarized and used to make recommendations for revising the video and the survey. The remainder of this report is divided into four sections. Methods are described in the next section, including the procedures for analysis. The results of the analysis of the survey responses follow. Next, recommendations for revising both the video and the survey are described. Additional details to support the text are contained in Appendixes A to D. These include a copy of the MTP survey, respondents' comments from the survey, and sample questions for a revised survey.

1 A second survey on this video was distributed through the Transportation Information and Communications Resource Center in Germantown, Maryland, to trainers and staff. Thirty-nine surveys were returned. The majority of respondents felt that the video was the correct length, understandable, and beneficial, with as many respondents marking one extreme on these components as the other. Further interpretation of this survey is not included in this report. 


\section{METHODS}

A random sample of 1,033 individuals who watched the video and then returned it to MTP received a one-page survey from MTP approximately three to six weeks after the video was shown. The survey consisted of nine parts: six brief questions and three requests for comments. The survey covered viewers' reaction to the video, how the video was used, and suggestions respondents might offer. (Appendix A contains a sample completed survey.) In the last two years, ${ }^{2} 695$ surveys were received by MTP and forwarded to the Argonne Film and Video Group, ${ }^{3}$ for a response rate of $67 \%$.

A coding scheme was developed to allow the information from the surveys to be analyzed. After entering the data and checking for agreement, the statistical program of the Statistical Package for the Social Sciences (SPSS) was used to determine frequencies and certain relationships.

Although the following results describe the information gleaned from the surveys and subsequent recommendations, there are limitations. The time elapsed between viewing the video and completing the survey, the ambiguous nature of the questions, and the cursory approach employed by respondents as they completed the survey (as evidenced by missed answers and brief responses) all contribute to reducing the usefulness of this survey and, in turn, the usefulness of what may be gained from its analysis.

2 The reporting period for this report was from October 1990 to March 1992.

3 It is unclear to what extent these viewers are representative of the potential audience (i.e., all teachers), since those who requested the video, but did not indicate whether they had shown it, were not part of the pool of individuals who were randomly sampled. 


\section{RESULTS}

This section is divided into three subsections: (1) types of respondents, (2) responses to the video, and (3) summary of results.

\subsection{TYPES OF RESPONDENTS}

Of the nearly 700 respondents to the MTP survey, over $94 \%$ (654) of the respondents were employed by a school, with most of these schools being junior or senior high schools. The other respondents were spread among universities (1.3\%), vocational centers $(0.5 \%)$, senior citizen centers $(0.8 \%)$, prisons $(0.03 \%)$, a hospital $(0.015 \%)$, a park $(0.015 \%)$, and others (3.3\%). Because most of the respradents who completed the survey were teachers, the following discussion is, for all practical purposes, about teachers. The breakdown of specific grade levels is shown in Table 3.1.

Only about $40 \%$ of the respondents indicated the classroom subject in which the video was shown, giving a small glimpse into the usefulness of the video. The coverage of this video appeared to be quite broad, including life science, drafting, health, English, and home economics; however, most respondents who completed this question showed the video to a science class (27\% of all respondents). The classroom subjects that were listed are found in Table 3.2.

The geographic distribution of the video blanketed the United States, with 25 or more respondents showing the video in 10 states (Table 3.3). No one requested the video in Alaska, Delaware, Washington, D.C., Hawaii, or Vermont. This distribution does not parallel the areas of high transportation activity for DOE; however, the distribution may reflect MTP's service area or the U.S. population.

TABLE 3.1 Specific Grade Levels Represented by Respondents

\begin{tabular}{lcr}
\hline \multicolumn{1}{c}{ Teacher's Level (Grades) } & $\begin{array}{c}\text { No. of } \\
\text { Responses }\end{array}$ & $\%$ \\
\hline Elementary (4th-6th) & 27 & 4 \\
Junior high (7th-8th) & 155 & 24 \\
Lower senior high (9th-10th) & 133 & 20 \\
Upper senior high (11th-12th) & 118 & 18 \\
Combined senior high (9th-12th) & 221 & 34 \\
& & \\
Total & 654 & 100 \\
\hline
\end{tabular}


TABLE 3.2 Subjects in Which Video Was Shown by Respondents

\begin{tabular}{lcc}
\hline \multicolumn{1}{c}{ Subject } & No. of & \\
& Responses & $\%$ \\
\hline Physical, life, earth, or other science & 68 & 10 \\
Science or general science & 54 & 8 \\
Chemistry, physics, or advanced science & 43 & 6 \\
Vocational studies, auto shop, or drafting & 29 & 4 \\
Environmental issues or ecology & 19 & 3 \\
Social studies or current issues & 22 & 3 \\
Driver's education, safety, or health & 17 & 2 \\
Home economics or adult or special & 10 & 1 \\
education & & \\
Business & 6 & 1 \\
Agriculture & 3 & 0.4 \\
English & 2 & 0.3 \\
Unknown & 422 & 61 \\
$\quad$ & 695 & 99.7 \\
\hline Total & & \\
\hline
\end{tabular}

TABLE 3.3 States Where 25 or More Respondents Requested the Video

\begin{tabular}{lcc}
\hline \multicolumn{1}{c}{ State } & $\begin{array}{c}\text { No. of } \\
\text { Responses }\end{array}$ & $\%$ \\
\hline California & 50 & 7.2 \\
Michigan & 49 & 7.1 \\
Pennsylvania & 38 & 5.5 \\
Texas & 36 & 5.2 \\
North Carolina & 30 & 4.3 \\
New York & 29 & 4.2 \\
Wisconsin & 26 & 3.7 \\
Iowa & 25 & 3.6 \\
Kansas & 25 & 3.6 \\
Oklahoma & 25 & 3.6 \\
\hline
\end{tabular}




\subsection{RESPONSES TO THE VIDEO}

\subsubsection{Ratings on Numerical Scales}

Two questions in the survey asked for respondents' general reaction to the video on scales of 1-10. The first asked for the respondents' memory of the viewers' rating and the second for the respondents' comparison of this video with other similar videos. Because of a lack of appropriate comparisons, a full $11 \%$ of the respondents did not answer this second question. In general, the respondents thought that the video was pretty good. It was not a unanimously great film, but many respondents seemed to be quite happy with it. Their ratings are summarized in Table 3.4 .

Positive reaction to the video was spread fairly well across the school levels to which the video was shown, with a slightly greater number of positive reactions from the high school teachers. Whereas $22 \%$ of the total group rated their viewers' reactions in the $9-10$ range, only $14 \%$ of the junior high/middle school teachers were in this category, compared to $25 \%$ of the senior high school teachers.

\subsubsection{Responses to Open-Ended Questions}

Two open-ended questions on the survey provided an opportunity for respondents to mention the strikingly good or bad aspects of the video and to comment on the information that they would like to see in other videos. Unfortunately, 306 respondents left both questions blank. Of those who wrote something, most gave short positive feedback. Most of

TABLE 3.4 Ratings of General Reaction to the Video

\begin{tabular}{lcc}
\hline & \multicolumn{2}{c}{ Respondents (\%) } \\
\cline { 2 - 3 } Rating & $\begin{array}{c}\text { Rating in } \\
\text { Viewers' } \\
\text { Rating }^{\text {a }}\end{array}$ & $\begin{array}{c}\text { Comparison with } \\
\text { Other Videos }\end{array}$ \\
\hline 9-10 (excellent) & 22 & 32 \\
7-8 (pretty good) & 53 & 37 \\
1-6 (not so good) & 23 & 20 \\
Total & 98 & 89 \\
\hline
\end{tabular}

a Because the respondents to the survey were mostly teachers, this column is their recollections of their students' opinions. 
these respondents also rated the video quite high by their own standards, but not necessarily excellent (49\% of those who gave positive, open-ended feedback rated the film as a 9 or 10 compared with others they had seen; $42 \%$ of these respondents rated the film as a 7 or 8 ; the remainder rated it as 6 or less [on a 10-point scale]).

The richness of the open-ended responses is best interpreted by a sample of the surveys. Of the 376 surveys sent in the last year (between October 1991 and March 1992), 117 respondents offered a written comment - their most important memory of the video. This type of response does not lend itself to tallying. The following discussion tharefore reflects the diversity and range of respondents' perspectives, rather than significant findings.

\subsubsection{General Comments about the Video}

This section is subdivided into three related topics: overview, video message, and curriculum. Most respondents gave only one comment in answer to each question; written responses were not dominated by a few individuals. Direct quotes from respondents are listed in Appendix B.

\section{Overview}

The first open-ended question asked for general comments about this video. As a result, some respondents chose to summarize the highlights of the video, saying that the film was informative and showed the high incidence of hazardous transportation, while other responses were more general. Several mentioned that the subject and length contributed to classroom discussions, that the information was clearly explained and accurate, and that the visuals were effective.

Two respondents noted that the film was reassuring and that students felt better after viewing it. Thiese comments highlight the fact that despite the experts' view of the safety of transporting radioactive and hazardous materials, it is a subject that elicits concern and fear.

Other general comments reflected the importance of using media to convey aspects of critical, controversial environmental issues. Respondents were appreciative of the film's role in simply raising awareness.

Some respondents offered general but negative comments, ranging from complaints that the video was not interesting and that students lost attention, to comments that the video was too complex or too simple. Others thought that the video was old and needed to be updated. 


\section{Video Message}

Another category of the respondents' comments dealt with the content of the video. The crash tests were the only specific component that drew comments, and there were 20 such responses. According to these respondents, the accident scenes and package tests were exciting, interesting, and enjoyable for their students to watch. One respondent replayed the tape in slow motion to get a better view.

The excitement generated around these crashes might suggest that every transportation video shculd include crash tests. They seem to be a very memorable aspect of this film. It would be interesting to know if these images are so powerful that they eclipse the other messages of the video.

One question in the survey asked who sponsored the video. Only $14 \%$ of the respondents recalled the DOE. This is not surprising, because sperific detail is not well recalled from a video presentation, and this detail was not reinforcea repeaiedly.

Perhaps the most important critique of the video revolved around the degree to which some respondents thought that it was one-sided. Several respondents were quite insistent on this point, and one eloquent response is included here: "It was too one-sided! Students laughed at its bias. They didn't believe it. It's hard to explain, but I think that they laughed because their intelligence was being insulted. Their attitude was, Yeah, right..."

These comments point to the sensitive nature of this issue and how "unbiased" and "informational" messages that are closely tied to emotional and risk-related subjects can be perceived as "biased propaganda." Recognition of danger and of other perspectives may greatly enhance the message of safety or at least make the video appear to be a more balanced treatment of the issue. Indeed, the strongest suggestion for other videos was for a presentation of both sides of the issue.

\section{Curriculum}

One question in the survey asked how the video was used in the schools, including in what subjects the video was used. In the open-ended section, several respondents mentioned that the video made a good contribution to their unit on nuclear power, vocational studies, or current issues. Other respondents described the activities that they used with the video, such as mapping local transportation routes or discussing propaganda.

The fact that many respondents showed this video to several different classes (i.e., seventh-grade life science and 11th-grade physics) suggests that either the video was versatile, the respondent was highly organized, or the respondent was not too particular about content relevance. Other respondents admitted that they did not have a curricular connection to the video. It was used as a filler, for a change of pace, or on a day with a substitute. 


\subsubsection{Suggestions for Other Presentations}

Another ofen-ended question asked respondents about other aspects of "this subject" that they would like to see presented. This question gave respondents an opportunity to generate their wish list for more free films. It is interesting that respondents interpreted "this subject" very broadly, because they requested everything from "more on ecology" to "how science affects people's everyday lives." A complete list of their responses is in Appendix C.

Respondents also requested more information on topics specifically related to the video, such as placarding requirements, truck safety inspections, and environmental and health effects of accidents. Far more common, however, were suggestions for videos that were not directly related to transportation. The suggestions help define how respondents (particularly teachers) perceive this topic by describing the related information they need. Their needs extended from the safe disposal of nuclear fuel waste to the storage and disposal of hazardous wastes.

Regardless of the specific topic (storage, disposal, etc.), the most repeated theme among the requests was for a healthy presentation of both sides of each issue: health and environmental risks, history of accidents, safety precautions taken, how the issues are perceived by various advocates, etc.

The variety of connections that respondents made to this film is evidence of the confusion around the role of DOE regulations and responsibilities. Even though the DOE does not ship radioactive materials to hospitals or from nuclear power plants, should this or other videos explain the process? Although the video did not mention radioactive "waste," many respondents assumed that this indeed was the material being transported.

\subsection{SUMMARY OF RESULTS}

Despite the ambiguity of the questions and the quality of information provided, some conclusions may be drawn from these surveys. As mentioned previously, hi.. r, several limitations in the survey's design hamper the confidence with which one can urdw these conclusions:

1. Junior and senior high school students were the primary audience, with their teachers being the overwhelming majority of the respondents to this survey.

2. The video was well distributed across the country.

3. The topic appears to be flexible enough to be used in physical science, chemistry, life science, current events, driver's education, vocational studies, and economics classes. The video can also provide a topic for writing in language arts.

4. Most respondents thought that the video was pretty good. 
5. Respondents would like additional information about the controversial aspects of this and related topics - health effects, environmental consequences, potential dangers, and actual accidents.

6. Respondents associated this topic with hazardous waste disposal and nuclear power accidents, even though the theme was transportation.

7. The crashes were mentioned as a memorable and interesting component of the video. 


\section{RECOMMENDATIONS}

Although there are some limitations to the data, as described previously, this assessment suggests ideas for revising both the video and the survey. These ideas are discussed subsequently.

\subsection{REVISING THE VIDEO}

The following section suggests ways to revise the video to improve its effectiveness:

1. Assess the knowledge and perceptions of the audience(s). The purpose of creating a video is to communicate a certain message to a particular group of people. Once they have been identified (in this case, students and their teachers), it is critical to shape the message around what they already know and how they perceive the issue; for example, no respondent mentioned that the background information on radiation and radioactive exposure was helpful or that it was necessary. It may be possible to shorten this segment and target the video to high school students who already have this information.

A clear notion of the purpose of the video and the target audience may result in different videos for different audiences. Despite what these results communicate about teachers and their students, we still do not know much about emergency management responders and their impressions of the video. Separate evaluations may be needed to assess their opinions of the effectiveness of this video.

2. Design the video message to meet the needs of the audience. Given the responses in this survey and reports about risk perception (e.g., National Research Council 1989. Michaels 1990; Stern 1991; EPA 1992; Golding et al. 1992; Morgan et al. 1992; Rich et al. 1992), it appears that concerns about radioactive materials are quite different from those about hazardous materials. To effectively address each issue, it will probably be necessary to separate these topics and treat them in two videos. Because the regulations for transport of these two types of materials vary, two videos should make the information much clearer.

3. Specify the goals and objectives for each video. Such specification will provide a basis for determining if the video's message is appropriate and effective for the audience. Examples of statements of objectives include the following: (a) students will be able to explain that federal regulations govern the transportation of radioactive materials; (b) students will be able to state the DOE's role in the transportation of radioactive materials; (c) students will be able to list three ways in 
which accidents are prevented; and (d) students will be able to list three ways in which the severity of accidents may be reduced, should an accident happen. It may also be appropriate to consider the following two objectives for the teachers: (a) teachers will be able to use the video to illustrate various careers associated with the transportation of radioactive materials, and (b) teachers will be able to use the video to support an investigation into local concerns about nuclear power or transportation.

4. Review concepts and footage, choosing those that best meet the goals and objectives. Guidelines for the design of messages may be helpful at this point (e.g., Fleming and Levie 1978; Fazio and Gilbert 1981; Kaplan and Kaplan 1982). Of particular interest are studies on risk communication, which provide some helpful insights into presentations of this type. It is important to recognize that experts do not think about risk in the same way as the general public. The public includes far more variables in the definition of "risk" than do the experts, who limit their evaluations to the chance of death. Therefore, a video explaining the experts' rationale is unlikely to appease the public's concerns. A careful review of the many dimensions disturbing to people about the transportation of radioactive materials would be helpful.

5. Review the completed video for technical accuracy.

6. Pilot the completed video with the intended audience. Pilot the video with junior and senior high school students (intended audience) with a survey that directly tests if the concepts were understood and if the desired attitudes were developed.

7. Revise the video accordingly, and distribute.

\subsection{REVISING THE SURVEY}

The design of a survey is a balancing act between what you want to know and what the audience can tell you. Ultimately, it would be useful to know if and how the students' opinions about the transport of radioactive materials changed, but an MTP survey will most likely be answered by teachers, not students, so it is important to consider how teachers can provide the most helpful information.

Revising the survey will entail several steps. The first step in revising this survey is to define the audience. The next step is to list the critical issues for which respondents (i.e., teachers) can provide helpful information. In some cases, results from such a survey may be used to obtain increased funding for the outreach program, to justify expanding the distribution network, or to develop new programs. In other cases, a survey's results may improve the existing video, teacher's guide, or distribution procedures. The questions used 
in each case may be different. The objectives for the video and for the survey should be consistent.

The following recommendations provide general guidance for the design of a survey, with specific reference to this MTP survey. Sample questions that could be used in future surveys are provided in Appendix D. Additional useful questions may be developed once the objectives for the video and the survey are determined.

1. Design the survey's questions to address specific components and objectives of the video's message. For example, if one objective for the video is to show various career possibilities, then ask respondents to list careers that they saw illustrated or rate the degree to which they were made aware of different career options. Questions can be designed to tap new knowledge, changing attitudes, or even changing behaviors.

It is important to word the questions carefully so as to actually obtain the information that will address the objective. If knowing how teachers use this video in their classroom is important, it would be more helpful to know in which unit they are using the video, rather than in which class. If they use the video for more than one class (as many did), teachers must be instructed to complete a separate survey for each class, or the survey should be constructed to make clear which responses are from which class.

2. Ask questions that the respondents can easily answer, and give explicit directions. It is difficult to accurately lump all of the students' reactions to a video (six weeks later) into one number scale; for example, it may be more useful to request that teachers ask students how they would rate the video and record the numbers of students who voted for very interesting, somewhat interesting, and not interesting.

Another question in the MTP survey asked respondents to compare this video with "others you have seen." Regardless of their answer, if it is not clear with which videos the respondents are comparing this one, it is difficult to know if the video is good or bad according to the respondents. We know only how it rates compared with some unknown competition.

3. Use shorter rating scales. The scale of 1-10 gives a range that is wider than necessary. Four to five distinguishing points are generally adequate.

4. Ask questions that respondents understand. Several respondents admitted to not knowing what the sponsor of a video is. If this is a good measure of what the video is communicating, a better question might be, "What agency is featured in this video?" 
5. Do not embed multiple components in a question. One question asked about the grade and subject of the class that viewed the video. Fifty percent of the respondents answered only half of this question.

6. Use open-ended questions sparingly. Despite their appeal, one cannot tell how many respondents might have said the same thing if they had remembered it; however, open-ended questions are extremely useful early in the development of a survey in order to determine the range of possible opinions.

7. Do not ask questions where a negative response makes respondents look incompetent. Two questions in this survey fell into this category. Few respondents would admit to not introducing the video or not leading a discussion around it. Of greater interest might be the quality of the discussion or whether the respondents used the question-and-answer booklet to address students' questions or if the video was self-explanatory.

This effort at evaluation is an important step in assessing the impact of transportation outreach materials, such as videos, for the DOE. These results suggest that this video is primarily used in junior high and high school classes in diverse subjects. Most respondents also felt that this video was pretty good, although they wanted more information on diverse aspects of topics related to transportation of hazardous and radioactive materials. Indeed, while this evaluation is a critical step toward better understanding of the usefulness of transportation outreach activities, many questions remain unanswered. The complexities of the topic and the requests for information on many components of the topic suggest that future activities be geared toward additional evaluation - with particular emphasis on defining the audience(s) and its (their) needs, and on pilot-testing alternative approaches to message design that have been specifically tailored to meet the needs of particular audiences. 


\section{REFERENCES}

EPA: See U.S. Environmental Protection Agency.

Fazio, J., and D. Gilbert, 1981, Public Relations and Communications for Natural Resource Managers, Kendall/Hunt Publishing Co., Dubuque, Iowa.

Fleming, M., and H. Levie, 1978, Instructional Message Design Principles from the Behavioral Sciences, Educational Technology Publications, Englewood Cliffs, N.J.

Golding, D., et al., 1992, "Evaluating Risk Communication: Narrative vs. Technical Presentations of Information about Radon," Risk Analysis 12(1):27-35.

Kaplan, S., and R. Kaplan, 1982, Cognition and Environment: Functioning in an Uncertain World, Praeger, New York, N.Y.

Michaels, M., 1990, "Speaking the Language: Siting by Communication," Management of World Wastes 33(9):45-48.

Morgan, M.G., et al., 1992, "Communicating Risk to the Public," Environmental Science and Technology 26(11):2048-2056.

National Research Council, Committee on Risk Perception and Communication, 1989, Improving Risk Communication, National Academy Press, Washington, D.C.

Rich, R.C., et al., 1992, "Strategies for Effective Risk Communication under SARA Title III: Perspectives from Research and Practice," Environmental Professional 15:220-227.

Stern, P.C., 1991, “Learning through Conflict: A Realistic Strategy for Risk Communication,” Policy Sciences 24:99-119.

U.S. Environmental Protection Agency, 1992, Seven Cardinal Rules of Risk Communication, EPA 230-K-92-001, Washington, D.C., May. 


\section{APPENDLX A:}

\section{MODERN TALKING PICTURE'S SURVEY ${ }^{4}$}

\section{Film/Video Reaction Questionnaire}

Modern Talking Picture Service, Inc.

09-Mar-92 5000 Park Street North

St. Petersburg, Florida 33709

Film/Video Number 24356

A02331-00 10

Film/Video Title Trans Radio/Hazard Materials

Show Date 01/27/92 $81 \quad 14$

Organization

Name

Address

City, State, Zip Code

PLEASE ANSWER THE QUESTIONS BELOW AND RETURN THIS TO US IN THE ENCLOSED POSTAGE PAID ENVELOPE. THANK YOU.

1. On a scale of 1 thru 10 , how did your viewers rate this program?

Poor 12345678910 Excellent

2. Compared with others on the same subject, how would you rate it?

Poor 12345678910 Excellent

3. Was there any discussion before or after showing?

Yes No

4. Was it introduced?

Yes No

5. For what grade level and subject was this used?

10-12

6. If you recall, please name the sponsor.

Department of Energy

7. We would appreciate any general comments about this program.

The crash scenes were amazing; makes my students think.

8. What other aspects of this subject would you like to see presented?

9. We would appreciate any comments about our service.

Good service but sometimes not on time.

4 Used with permission of Modern Talking Picture Service, Inc., July 1, 1993. 


\section{APPENDIX B:}

\section{SAMPLE OF RESPONDENTS' COMMENTS ON THIS VIDEO}

The following represents a sample of the variety of responses to the open-ended questions about the video:

- Overview positive

- Leads into discussions well.

- Length was good; left room in the period for questions and comments.

- Good illustrations and photography.

- Class paid attention; it sparked discussion.

- Very informative and historically correct.

- Overview negative

- Not as interesting as other films we have watched.

- A little too complex and slow moving for my seventh graders.

- Good information but on the dry side.

- The film didn't keep my students' interest.

- Issue Awareness

- Nuclear waste is a very controversial issue in Wisconsin.

- Very informative; the class saw what science does and how science protects the public.

- This program was good for us because two days later, we had a tanker carrying zinc wreck about a half mile from our school.

- Real eye-opener to anyone really concerned.

- Very interesting; showed us things we normally don't see or even hear about.

- Good; it gave the students some insights as to the complexity of various problems that confront our society.

- The subject matter is a concern of our more knowledgeable students.

- Pertinent because the Waste Isolation Pilot Plant (WIPP) site is in New Mexico.

- Video Message

- Students and I enjoyed the film, particularly testing of containers.

- The testing done on structures holding the radioactive material was impressive and dramatic.

- The crash scenes were amazing; makes my students think.

- We stopped the film several times so we could see the container fall in slow motion.

- The film was good and held the attention of the students better than many films. The students were really impressed with the crash tests of containers. 
- Curriculum

- We use these films for students to look at vocational opportunities.

- Great; a nice addition to our nuclear power unit!

- I incorporated the program with our study of the advantages and disadvantages of nuclear energy.

- For my chemistry classes, the video allowed discussions regarding properties of containment materials.

- All of my seventh, eighth, and ninth grade classes (energy power transport and community systems) watched the film and had to draw two routes in the county on maps and describe them.

- Interesting filler with a serious message.

- I used it as a change-of-pace subject; not included in a unit.

- Even when the videos arrive late and I'm covering another topic, I can usually find some relevance.

- With most videos, the sponsor is trying to sell a point; our discussions are mainly about how to look at the video and reach conclusions. 


\section{APPENDIX C:}

\section{SAMPLE OF DESIRED TOPICS}

The following represents a sample of the topics and information respondents would like to have in video/film format.

- Information on transportation of materials

- Placarding and material identification

- Transport of hazardous materials (HazMat) by aircraft

- Requirements for drivers' licensing

- Truck safety inspections

- HazMat placarding

- Transport of radioactive materials

- Containers and labels

- Special handling methods for hazardous materials

- Route planning

- Scenarios where a waste container doesn't survive

- Dangers of contaminated waste transport

- Precautions taken in case of accidents with high-level material

- Related information on transportation

- What other nations are doing

- National policies and laws regarding the environment

- Graphics of the magnitude of the problem of waste generation

- Controversies

- Tour of the Waste Isolation Pilot Plant (WIPP) site

- How does a particle accelerator work?

- Disasters caused to the environment by misuse and. roper handling of hazardous and radioactive materials

- Historic accidents and how they have been cleaned up

- Problems in environmental protection

- Flip side: hazards involved with radioactive materials

- How spills are handled

- Organized pros and cons

- Environmental and health dangers of radioactive materials

- Effects of actual accidents

- What happens when radioactive packages fail, as they will

- Why are some people concerned, and are these concerns valid?

- Negative effects of disposal of waste

- Burning radioactive and hazardous wastes 
- Nuclear power and related concerns

- When, where, and how will we get rid of nuclear waste?

- Reference to Chernobyl

- Power plant safety records

- More films on pros and cons of nuclear power

- Health effects of varying amounts of radiation

- Disposal of nuclear waste

- Storage of nuclear waste

- Number of nuclear plants we have and amount of waste they generate

- Low-level nuclear waste sites

- Disposal of radioactive waste

- Future of nuclear power, especially after the Gulf War

- Impact of closing nuclear power plants nationwide

- Information on storage of transuranic wastes

- Underground storage of spent fuel and test feasibility

- Hazardous waste and related concerns

- What is hazardous waste?

- Specific environmental effects of various toxins

- Current accepted methods for handling toxic chemicals

- Disposal and treatment of hazardous waste

- Cleaning up hazardous material spills

- Where we put hazardous wastes and who controls that

- Treatinent of hazardous wastes

- Hazardous chemicals in schools and homes

- Reclaiming hazárdous matərials 


\section{APPENDIX D: \\ SAMPLE QUESTIONS FOR A REVISED SURVEY}

The following samrle questions for a new survey are provided under major conceptual categories. Once the objectives for the video and survey have been confirmed, other questions may be appropriate. Specific formatting of the questions and overall layout of the survey would be determined after specific questions are agreed upon.

Classroom Use (If it is important to understand how the video is being used so that supplementary materials or a teacher's guide can be designed, these questions may be helpful.)

1. Check in what unit you used this video. (You may check more than one.)

Nuclear power or nuclear energy

Current issues around energy

Technological advances

Environmental health and protection

Human health and protection

Radioactivity

Vocational studies

No unic

Other (specify)

2. Check why you used this video in your classroom. (You may check more than one.)

Part of a unit

Transition between units

- Change of pace

To generate discussion

- To provide a writing assignment

To demonstrate various careers

Loral issue of concern

Price was right

Other (specify)

3. Circle how well the following enabled you to use this video effectively. $(i=$ not very well; $3=\mathrm{OK} ; 5$ = very well $)$

a. Question-and-answer booklet

b. Timely arrival of video

c. My own textbook

d. The fair, unbiased presentation

e. Teacher's guide

f. Other (specify)
12345

12345

12345

12345

12345

12345 
Message Design (To change the video, it may be helpful to understand how viewers see the current version.)

4. Circle how important the following would be to improve this video. ( 1 = not important; 3 = moderately important; 5 = very important)
a. Shorten it.
12345
b. Lengthen it.
12345
c. Shorten the basic explanation on radioactivity.
12345
d. Include information about real accidents.
12345
e. Include more crash tests.
12345
f. Explain the risks.
12345
g. Describe transportation safety procedures.
12345
h. Use less technical terms.
12345
i. Other (specify)
12345

Communication of Major Concepts (In assessing the video, it is necessary to understand whether viewers are indeed learning the message intended in the video.)

5. Circle how well the video communicated these major concepts to you. ( 1 = not very well; $3=\mathrm{OK} ; 5=$ very well; $X=$ don't know)
a. Transportation of radioactive materials can be safe.
$12345 \mathrm{X}$
b. Government agencies have a strong history of safety.
$12345 \mathrm{X}$
c. Regulations are effective for this material.
$12345 \mathrm{X}$
d. Many radioactive materials need to be transported.
$12345 X$
e. Citizens are protected.
$12345 \mathrm{X}$
f. There are many sides to complex issues.
$12345 \mathrm{X}$
g. Other (specify)

6. Circle how important the following aspects are in contributing to the video's success in your classroom.

( 1 = not important; 3 = moderately important; 5 = very important;

$\mathrm{X}=$ don't remember)
a. Woman in the store buying things
$12345 \mathrm{X}$
b. Explanation of radioactivity
$12345 \mathrm{X}$
c. Explanation of radiation exposure
$12345 \mathrm{X}$
d. Discussion of regulations and policies
$12345 \mathrm{X}$
e. Explanation of placards and labels
$12345 \mathrm{X}$
f. Water and fire tests of packages
$12345 \mathrm{X}$
g. Truck crashes to test containers
$12345 \mathrm{X}$ 
7. Please rate the manner in which each aspect was presented.

$(1=$ too simple or unnecessary; we already knew it

$2=\mathrm{a}$ bit too simple

$3=$ perfect

$4=\mathrm{a}$ bit too complex

$5=$ too complex; not enough explanation

$\mathrm{X}=$ don't remember)
a. Woman in the store buying things
$12345 \mathrm{X}$
b. Explanation of radioactivity
$12345 \mathrm{X}$
c. Explanation of radiation exposure
$12345 \mathrm{X}$
d. Discussion of regulations and policies
$12345 \mathrm{X}$
e. Explanation of placards and labels
$12345 \mathrm{X}$
f. Fire and water tests of packages
$12345 X$
g. Truck crashes to test containers
$12345 X$

Attitudes toward the U.S. Department of Energy (Respondents' views and their receptivity to learning new information are related to their view of who is providing the information. The following set of items is designed to ascertain the viewers' image of the DOE.)

8. Circle how you feel about the following statements.

( 1 = strongly disagree; $2=$ disagree; $3=$ neutral; $4=$ agree; $5=$ strongly agree)

a. The U.S. Department of Energy does not prevent

12345 contamination problems at the existing nuclear testing and production sites.

b. The U.S. Department of Energy is responsible for

12345 transporting most of the radioactive material across this country.

c. The U.S. Department of Energy helps watchdog the nuclear industry.

d. I worry about the safety of nuclear power plants.

$12 ?+5$

e. I worry about radioactive contamination from transportation accidents.

f. The U.S. Department of Energy does a reasonable

12345 job of safeguarding the public from potential hazards of transporting radioactive materials.

g. The transportation rules and regulations need to be better enforced to protect the public. 

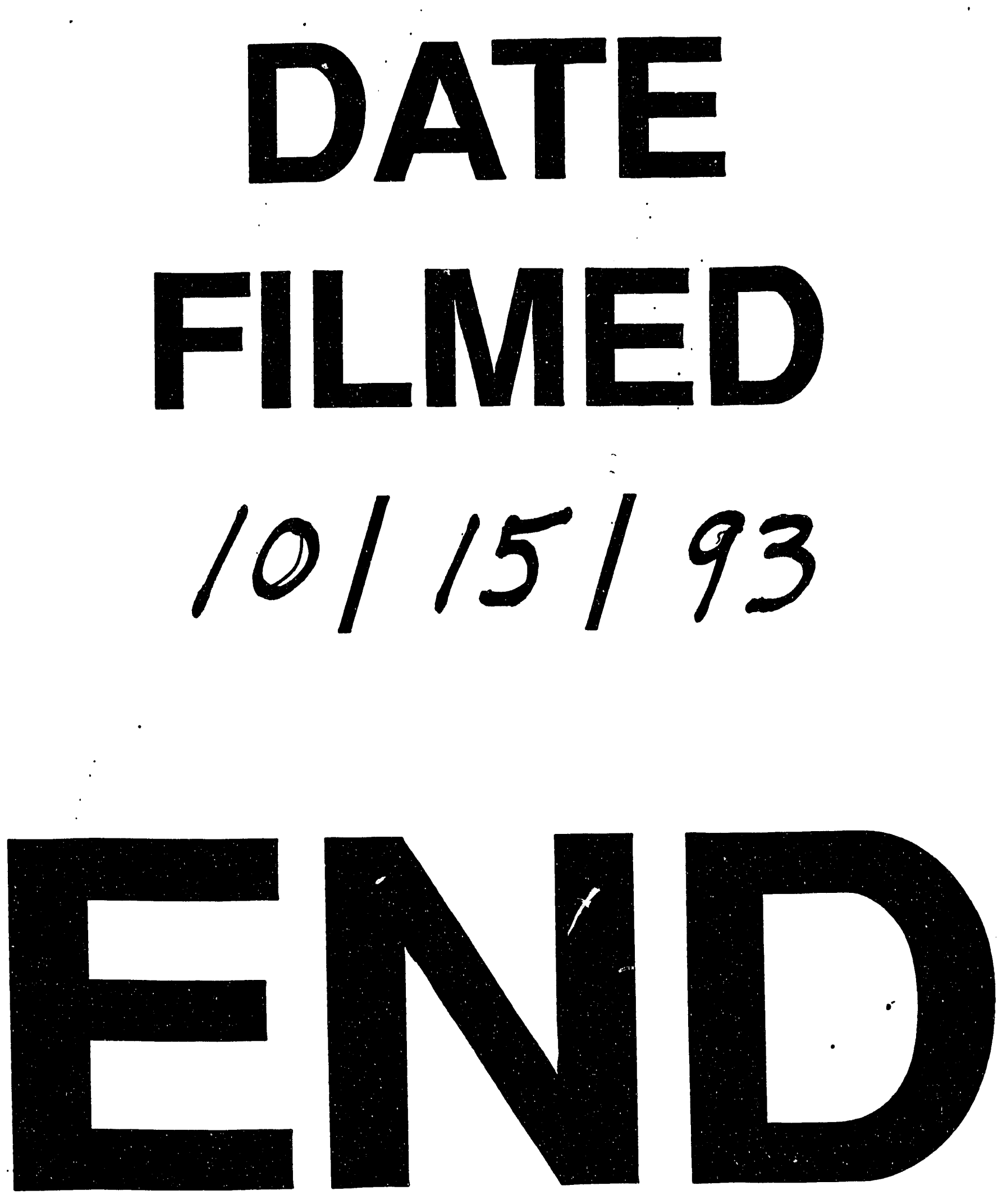


$$
\text { . }
$$

